\title{
ALGORITHM DESIGN FOR SHIP'S STEERING WITH SPECIFIED LIMITATIONS UNDER VARIOUS WEATHER CONDITIONS
}

\author{
UDC 66.012-52:364-781.2:006.015.8
}

Original scientific paper

\begin{abstract}
Summary
The problems of developing the risk assessment methods to estimate the level of safety of the vessel under the current conditions on a planned route before staring the pilotage as well as to make the decision on the beginning or suspension of pilotage in order to increase the level of navigational safety are discussed in the paper. Moreover, the application of the research results will reduce the affect of the human factor in decision-making in tasks related to the sea-going vessel's operation. The developed method for the quantitative assessment of navigational risks will improve the safety of ship's pilotage. It can also be applied in the decision-making support systems for the navigator in case of collision avoidance actions. The research results presented in this paper can be used to create automatic control systems.
\end{abstract}

Key words: $\quad$ safety of navigation; human factor; risk assessment; pilotage; automatic control

\section{Introduction}

In the modern period of large and active automation of sea transportation, collision of a ship with a fixed obstacle remains a very serious and active problem. There are many developed theoretical and practical solutions, which are mainly based on the concept of ship maneuvering and route planning algorithms. One of the main causes of accidents in maritime transport (Transport of Russia) continues to be the human factor, which in turn is the result of insufficient formalization of the ship steering process. An example is COLREGs-72 in which all the rules associated with the collision avoidance actions do not have clear decision-making criteria but rely primarily on the practical experience of the OOW. Another example is the pilotage of a ship through narrows, where everything depends on the pilot's and master's experience $[1,2]$.

IUMI (The International Union of Marine Insurance) statistics show that the losses of ships in the world fleet amounted to about $0.5 \%$ of the total composition in $1990,0.3 \%$ in 1996 and $0.1 \%$ in 2006 . We can assume that in this respect, safety at sea has increased almost 
Ivanovsky Nikolay, Chernyi Sergei,

Sokolov Sergey, Zhilenkov Anton, Zhinchenko Anton
Algorithm design for ship's steering with specified limitations under various weather conditions

5 times in 15 years! However, the same statistics show that the number of major ship accidents has increased significantly over the recent period (228 cases in 1998 and 720 in 2011). Insurers' data give an idea of the main types of ship accidents: about $35 \%$ malfunctions of ship mechanisms, $25 \%$ - grounding, $22 \%$ - collisions, about $13 \%$ - fires and explosions on board [3].

The manifestation of events of collisions with ships, touching the bottom of the ground, collisions with artificial obstacles can lead to various kinds of negative factors and consequences [4-7]. The main consequences of errors in the management of ships should be taken as the appearance of holes, the ingress of water into the ship's hull, which can lead to loss of buoyancy and the outbreak of fire, and the action in conditions of difficult climatic factors simply makes this situation several times worse and increases the risk of death of the ship and the crew.

When a vessel passes narrow straits with sharp turns under various weather conditions, they have a significant impact on the parameters of the vessel's motion and thereby affect the safety of the passage of the strait. The ship steering algorithm should take into account the current weather conditions in the strait (speed module, direction of flow, speed and direction of wind and waves, the depth of the channel line).

Let us consider this problem as an example of transit pilotage through Kerch Yenikalsky Canal. Kerch - Yenikalsky Canal (Fig. 1) is a complex hydraulic structure, which is part of the recommended route No. 12 from the Black Sea to the Sea of Azov. Kerch Yenikalsky Canal consists of four bends (Table 1) with a total length of $35050 \mathrm{~m}$. The minimum guaranteed depth and declared draft of the vessel within the canal are $8.3 \mathrm{~m}$ and 8.0 $\mathrm{m}$, respectively (according to 2017). The width of the navigable part of the canal is 120 meters throughout. The predominant depths beyond the canal edges are 6-7 meters for the Pavlovsky and Chushkinsky bends, 5-6 meters for the Burunsky, and 3-4 meters for the Yenikalsky bend. The Yenikalsky bend of the canal in the vicinity of Cape Ak-Burun crosses the transport passage through the Kerch Strait $[1,8]$

Table 1 Kerch - Enikale Canal

\begin{tabular}{|l|l|c|c|}
\hline $\mathbf{N}$ & Name of the bend & Length, $\mathbf{m}$ & $\begin{array}{c}\text { Heading of the axis, } \\
\text { degree }\end{array}$ \\
\hline 1 & Pavlovsky & 8570 & $356.6-176.6$ \\
\hline 2 & Burunsky & 3650 & $37.5-217.5$ \\
\hline 3 & Yenikalsky & 14650 & $66.8-246.8$ \\
\hline 4 & Chushkinsky & 8180 & $14.3-194.3$ \\
\hline
\end{tabular}

As per administrative division, Kerch - Yenikalsky Canal is approaches to the seaports of Kerch and the Caucasus. Navigation there is regulated by the By-Laws of the seaports of Kerch and the Caucasus. Vessels up to 252 meters and a draft of not more than eight meters are permitted to navigate along the Kerch - Yenikalsky Canal [1, 5, 8].

There are restrictions in visibility, but there are no restrictions in the wind regime. The Kerch Strait is characterized by complex hydrometeorological conditions, the prevailing winds are N, NW, NE, and SE. NE winds often reach speeds of $20 \mathrm{~m} / \mathrm{s}$ or more. The currents in the strait are wind-induced, the speed reaches 2 or more knots, the action of the current is especially pronounced in the area of the transport passage, as well as in the area of Cape Enikale. 
The above hydrological and hydrometeorological factors, as well as the relatively small width of the channel and shallow depths behind the edges make Kerch - Yenikalsky canal difficult to navigate and create the need for master to engage the pilot with local knowledge.

In turn, in the absence of restrictions in regulatory documents, the pilot needs a method for assessing the safety of the passage of the vessel within a planned route (channel) under actual conditions before the pilotage begins, i.e. in accordance with the preset parameters of the vessel and hydrometeorological factors, it would be possible to assess the risk for the vessel navigating through the strait, as well as her passage through the navigable passage under the Crimean Bridge.

To solve this problem, it is necessary to have a base of mathematical models of ships, and in case of its absence, to have a method for constructing a probabilistic model with minimal information about the ship (basic particulars, draft). The solutions to this problem are described in.

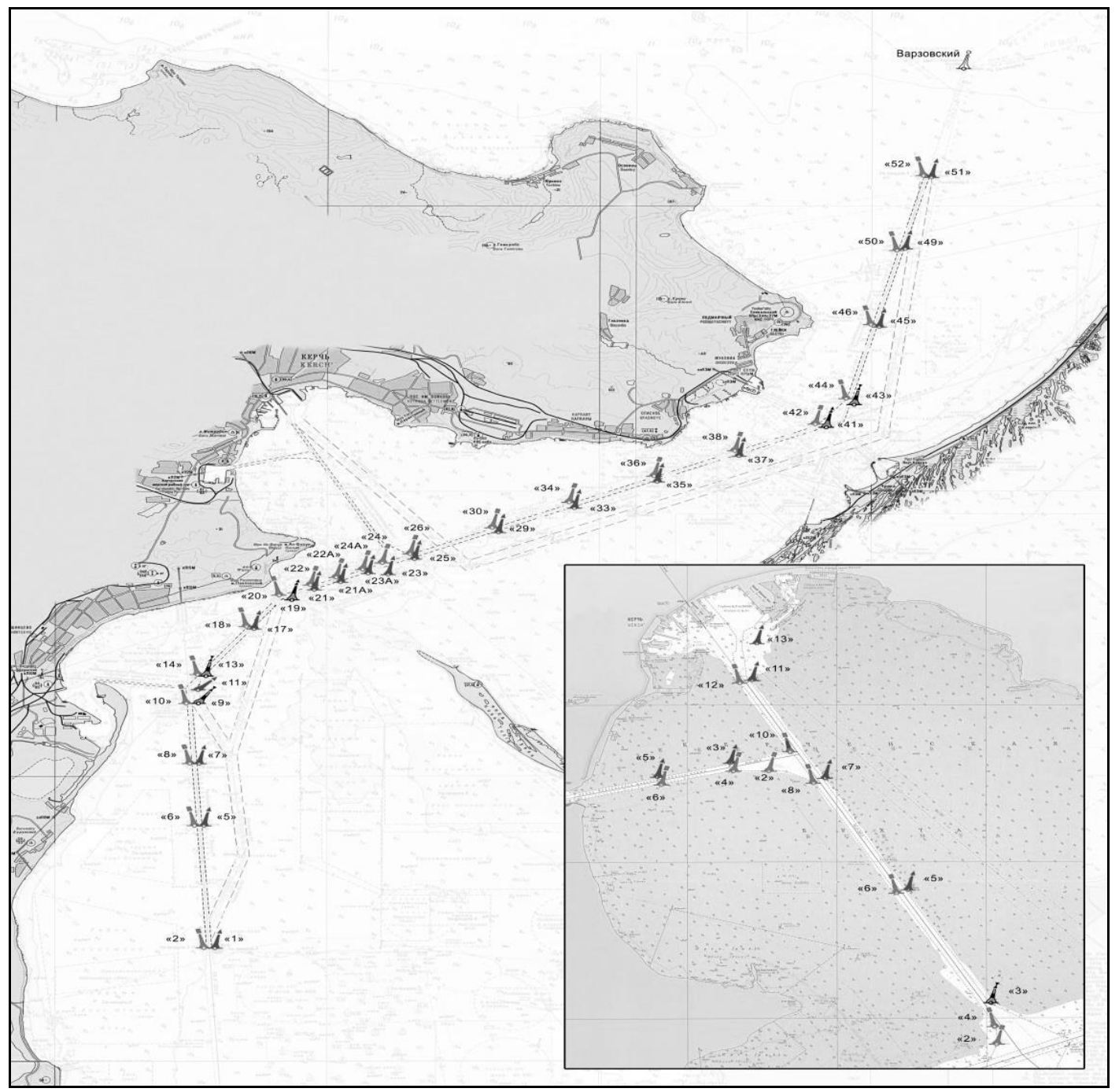

Fig. 1 Kerch - Yenikalsky Canal and Kerch Approach Canal with floating aids to navigation

The stage of development of navigation methods in our time is characterized by the presence of contradictions between the requirements of the complete (absolute) safety of the operation of water transport and the presence of a sufficiently high level of navigation 
accidents and incidents. It is this circumstance that gives rise to the need to improve methods for assessing navigation risks, and also determines the relevance of researching problems associated with a comprehensive solution to the problem of managing navigation risks in the industry.

One of the tools for influencing the level of risk is monitoring the development of the situation of approaching ships by coastal systems, for the full functioning of which it is necessary to integrate modern systems for lighting the navigation situation, which include modern radar stations and automatic identification systems [5, 9].

To develop optimal algorithms for the vessel steering, it is necessary, first of all, to develop appropriate mathematical models for a certain strait, type of vessel, weather characteristics. The structural and logical diagram of the automated steering system is shown in Figure 2.

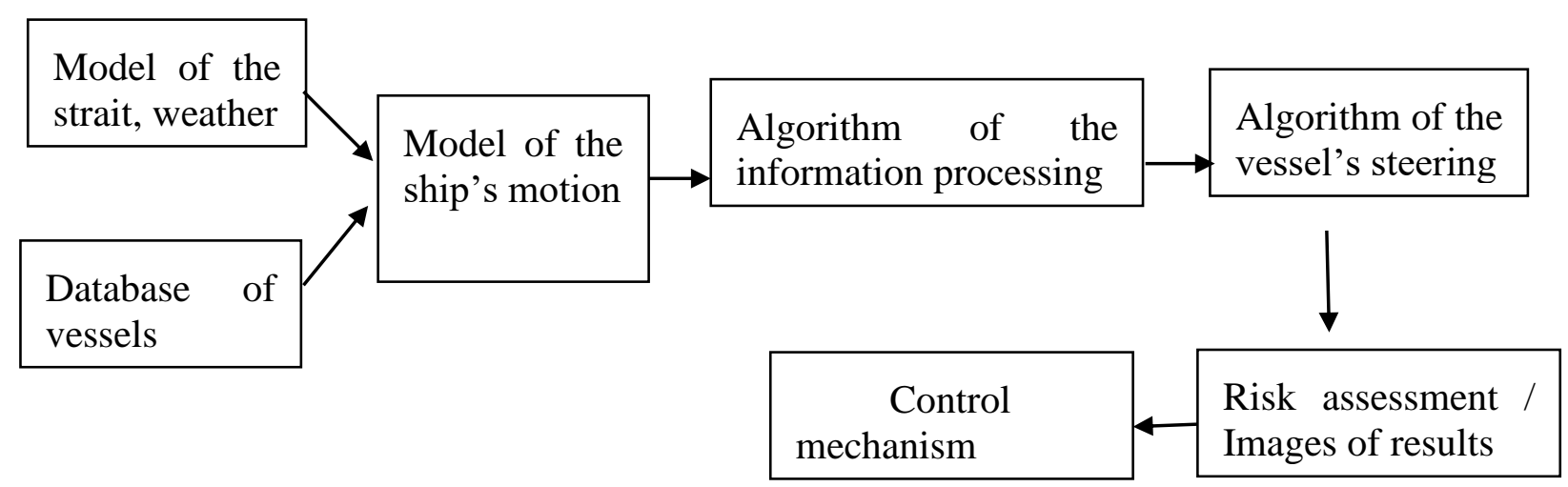

Fig. 2 Block diagram of an automated control system

The basic aspects that make navigation a rather specific industry with a high-risk zone: ships are limited and isolated systems, autonomous in terms of fuel supply, they have limited human capabilities and resources, and their actions when faced with dangers are limited. The characteristics described have transformed merchant shipping into high-risk activities, where navigational error or error in normal port operations can escalate to injury or loss of life, property damage and, in some cases, irreparable damage to the environment. Operational and environmental risks, resulting in an increase in costly claims and claims, are now a serious issue for shipowners, and the assessment of data and other risks is a necessary requirement for the safety of merchant shipping. The development of algorithms and the software implementation of these algorithms will allow one to create a hardware implementation (for example, in the form of a plotting board) of an automated system of the ship's steering in various weather conditions. Such a hardware implementation will make it possible, in an unrealistic time scale, to assess the likelihood of a safe passage of a particular ship through a certain strait under current weather conditions.

\section{Materials and methods}

The navigation system in our time should be positioned as a complex organizational and technical system, a multifunctional structure.

This system most reflects the social special processes of navigation, the stochastic and dynamic nature of environmental factors affecting the navigation process, the ability of navigators to analyze the navigation situation, to make correct (optimal) decisions for maneuvering. 
The relevance of the research cited in this paper is determined by the demand of practice. The amount of accidents involving the passage of vessels through the narrows are still high. The significance of this problem attracted a large number of researchers [9-11] to its solution. Almost all existing mathematical methods [12] formed the basis of the solutions. However, the task of assessing the risk of piloting the vessel at the planning stage of the operation was not solved. In our opinion, the reason is the lack of methods for quantifying risk taking into account the maximum number of influence factors. In the tasks of evaluating the basic parameters of the vessel under operational conditions were solved, which made it possible to assess quantitatively the navigation risks when navigating the vessel in a certain water area.

Control over ensuring the safety of navigation is a complex task, the main aspects of which are: international, regional and national laws and regulations; control is carried out by a number of institutions; control affects the different life cycles of the vessel. A significant disadvantage of the considered methods is that they reduce the navigation situation for the water area to a set of "ship-to-ship" pairs and the lack of a solution to the problem for several (group) ships as a whole [13]. With the exception of Davis's "active domain", all the described concepts do not provide a full-fledged opportunity for working in confined waters. Research in the field of ensuring the navigational safety of collective ship traffic, aimed at developing new approaches, devoid of the listed disadvantages, remains relevant. The most promising way to solve this problem seems to be the use of model representations based on the ideas of fuzzy logic systems and algorithms. They make it possible to comprehensively take into account the peculiarities of navigation in a specific water area and the "subjective" component when making decisions by the captain and / or operator of the coastal vessel traffic control system [14]. Comparison of risk methods is presented in Table 2.

Table 2 Methods for assessing the risk of collision of ships

\begin{tabular}{|l|l|l|l|l|l|l|}
\hline $\begin{array}{l}\text { Method or } \\
\text { Model }\end{array}$ & $\begin{array}{l}\text { International } \\
\text { Rules of } \\
\text { Preventing } \\
\text { Collision at } \\
\text { Sea, COLREGS }\end{array}$ & $\begin{array}{l}\text { Quantity } \\
\text { ships } \\
\text { more than } \\
\text { 2 }\end{array}$ & $\begin{array}{l}\text { Water } \\
\text { level limit }\end{array}$ & $\begin{array}{l}\text { Dynamic } \\
\text { model } \\
\text { movement } \\
\text { ship }\end{array}$ & $\begin{array}{l}\text { The } \\
\text { change } \\
\text { course } \\
\text { ship }\end{array}$ & $\begin{array}{l}\text { Change } \\
\text { ship speed }\end{array}$ \\
\hline $\begin{array}{l}\text { Ship } \\
\text { domain } \\
\begin{array}{l}\text { Fujii and } \\
\text { Tanaka }\end{array}\end{array}$ & - & - & - & - & - \\
\hline $\begin{array}{l}\text { Ship } \\
\text { domain } \\
\text { Goodwin }\end{array}$ & + & - & - & - & - & - \\
\hline $\begin{array}{l}\text { Ship } \\
\text { domain } \\
\text { Davis }\end{array}$ & + & - & + & - & - & - \\
\hline $\begin{array}{l}\text { Ship } \\
\text { domain } \\
\text { Codueella }\end{array}$ & + & - & - & - & - & - \\
\hline $\begin{array}{l}\text { Ship } \\
\text { domain } \\
\text { Collie }\end{array}$ & + & - & - & - & - & \\
\hline $\begin{array}{l}\text { Ship } \\
\text { domain } \\
\text { Tszyu }\end{array}$ & + & - & - & - & - & \\
\hline
\end{tabular}


The known methods for planning the trajectory of a safe movement of a ship can be divided into two categories: deterministic and heuristic.

An important aspect of risk assessment in navigation is the development of a method by which the results of risk analysis can be presented in recommendations on the acceptability of complex systemic risk, as well as the degree to which it is advisable to take a set of measures or actions necessary to reduce this risk. Risk criteria are the basis of this method $[15,16]$.

Deterministic methods are based on precise mathematical models and a well-defined sequence of calculations. Heuristic methods seek a solution within a subspace of possible acceptable solutions. Although the solution they found may not formally be the best (global extremum), it is quite suitable for everyday navigation practice. In the practice of navigation, it is believed that each navigation situation is unique in its own way, the ship is an inertial object with a very complex and difficult to simulate movement, therefore, the participation of the vessel traffic system operator and the navigator with their experience in decision-making is completely necessary.

The purpose of the research is to develop an algorithm for steering the vessel during the passage through narrows.

\section{Synthesis problem statement}

The controlled motion of the vessel in the horizontal plane with a current available and under various weather conditions is determined by a system of nonlinear equations [13]:

- equations of motion in a local fixed Earth system of reference

$$
\begin{aligned}
& \frac{\mathrm{d} x}{\mathrm{~d} t}=v_{x} \cos (\psi)-v_{y} \sin (\psi)+v_{T} \cos \left(\psi_{T}(x)\right), \\
& \frac{\mathrm{d} y}{\mathrm{~d} t}=v_{x} \sin (\psi)+v_{y} \cos (\psi)+v_{T} \sin \left(\psi_{T}(x)\right) ;
\end{aligned}
$$

- equations of motion in a body-fixed system of reference [8]

$$
\begin{aligned}
& \frac{\mathrm{d} v_{x}}{\mathrm{~d} t}=\frac{\left(\begin{array}{l}
F_{x i}\left(v_{y}, \omega_{z}\right)+F_{x g}\left(v_{x}, v_{y}, \omega_{z}\right)+F_{x r}\left(v_{x}, v_{y}, \omega_{z}, \delta\right) \\
+T_{v}\left(v_{x}, v_{y}, n_{o \sigma}\right)
\end{array}\right)}{m_{11}+a_{x T}+a_{x A}+a_{x V}}, \\
& \frac{\mathrm{d} v_{y}}{\mathrm{~d} t}=\left(\begin{array}{l}
F_{y i}\left(v_{x}, \omega_{z}\right)+F_{y g}\left(v_{x}, v_{y}, \omega_{z}\right) \\
+F_{y r}\left(v_{x}, v_{y}, \omega_{z}, \delta\right)
\end{array}\right) / m_{22}+a_{y T}+a_{y A}+a_{y V}, \\
& \frac{\mathrm{d} \psi}{\mathrm{dt}}=\omega_{z}, \\
& \frac{\mathrm{d} \omega_{\mathrm{z}}}{\mathrm{dt}}=\left(\begin{array}{l}
M_{z i}\left(v_{x}, v_{y}, \omega_{z}\right)+M_{z g}\left(v_{x}, v_{y}, \omega_{z}\right) \\
+M_{z r}\left(v_{x}, v_{y}, \omega_{z}, \delta\right)
\end{array}\right) / J_{z}+a_{\omega T}+a_{\omega A}+a_{\omega V}, \\
& X\left(t_{0}\right)=\left(x\left(t_{0}\right), y\left(t_{0}\right), v_{x}\left(t_{0}\right), v_{y}\left(t_{0}\right), \psi\left(t_{0}\right), \omega_{z}\left(t_{0}\right)\right),
\end{aligned}
$$


where $v_{T}$ is the current velocity module; $\psi_{T}(x)$ is the canal angle;

$a_{x T}, a_{y T}, a_{\omega T}, a_{x A}, a_{y A}, a_{\omega A} a_{x V}, a_{y V}, a_{\omega V}$ are linear and angular accelerations a result of the current, wind and waves, respectively.

The task of synthesizing the ship steering algorithm is that, in the process of the ship's motion, it is required to form the vector of control response $\mathbf{U}(\mathrm{t})$ (orders for the angular position of the rudder of the vessel) based on the estimated the present motion parameters $\hat{\mathrm{X}}\left(\mathrm{t}_{i}\right)=\left(\hat{\mathrm{x}}\left(\mathrm{t}_{i}\right), \hat{\mathrm{y}}\left(\mathrm{t}_{i}\right), \hat{\mathrm{v}}_{\mathrm{X}}\left(\mathrm{t}_{i}\right), \hat{\mathrm{v}}_{\mathrm{y}}\left(\mathrm{t}_{i}\right), \hat{\Psi}\left(\mathrm{t}_{i}\right), \hat{\omega}_{\mathrm{Z}}\left(\mathrm{t}_{i}\right)\right)$ (position, speed, angular position and angular velocity of the ship's circulation), so that the true parameters of the vessel $X(t)=\left(x(t), y(t), v_{x}(t), v_{y}(t), \psi(t), \omega_{z}(t)\right)$ as much accurate as possible should reproduce the desired $X_{g}(t)=\left(x_{g}(t), y_{g}(t), v_{x g}(t), v_{y g}(t), \psi_{g}(t), \omega_{z g}(t)\right)$ based on the minimization criterion risk values

$$
R=\int_{\Omega}\left[F(\Delta P) \frac{1}{P} \int_{t_{0}}^{T}\left[\Delta X(\tau) Q(\tau) \Delta X^{T}(\tau)+q(\tau) \delta(\tau)^{2}\right] \mathrm{d} t\right] \mathrm{d} \Delta P,
$$

where $\mathrm{M}$ is the compute statement of the average value, $\Delta X(t)=X_{g}(t)-X(t), \delta(\tau)$ are control response at the control time interval $t_{0}<=\tau<=T$.

The synthesis problem is solved under the assumption that the ship's motion model is linearized with respect to the reference motion, there are optimal linear estimates of the ship's parameters and current motion parameters [9], and the optimal control algorithm is synthesized in the class of linear algorithms.

\section{Mathematical models of the strait and weather conditions}

The strait is determined in the local fixed Earth system of reference by the fairway line $y=F_{f}(x)$, the width of the channel $D_{p r}$, and the depths on the line of the fairway $h_{p r}(x)$. The depths on the fairway line significantly affect the attached masses and the moment of inertia of the vessel. In addition, forces and moments of a viscous nature arise. The influence of depths is taken into account using the relevant coefficients, according to [16,17].

The current on the fairway line is considered as some transport velocity of water through which the vessel makes relative motion. The flow is determined by the constant module of velocity $v_{T}$ and the angle of the flow heading on the fairway line $\psi_{T}(x)$.

When the vessel proceeds in the strait with the flow in a body-fixed system of reference, accelerations occur.

The linear and angular accelerations from the flow are determined by the expressions [16].

$$
\begin{aligned}
a_{x T}= & -v_{T}\left(\left(m_{22} / m_{11}+1\right) \omega_{z}-\omega_{T}\right) \sin \left(\psi_{T}(x)-\psi\right), a_{y T}= \\
& -v_{T}\left(\left(m_{11} / m_{22}-1\right) \omega_{z}+\omega_{T}\right) \cos \left(\psi_{T}(x)-\psi\right), \\
a_{\omega T}= & -v_{T}\left(m_{22}-m_{11}\right)\left(\begin{array}{l}
v_{y} \cos \left(\psi_{T}(x)-\psi\right)-v_{x} \sin \left(\psi_{T}(x)-\psi\right) \\
-v_{T^{*}} \cos \left(\psi_{T}(x)-\psi\right) \sin \left(\psi_{T}(x)-\psi\right)
\end{array}\right) / J_{z},
\end{aligned}
$$


where $\omega_{T}$ is an angular velocity of the current bend in the fairway line

$$
\omega_{T}=\frac{\mathrm{d} \psi_{T}(x)}{\mathrm{dx}} \frac{\mathrm{d} x}{\mathrm{~d} t}=\frac{\mathrm{d} \psi_{T}(x)}{\mathrm{d} x}\left(v_{x} \cos (\psi)-v_{y} \sin (\psi)+v_{T} \cos \left(\psi_{T}(x)\right)\right.
$$

The concepts of true and relative wind are used to describe the effect of wind on ship's movements. The true wind is determined in the local fixed Earth system of reference by the velocity module $v_{A}$ and the angular direction $\gamma_{A}$, the relative wind is determined in the bodyfixed system of reference by the velocity module $v_{\kappa}$ and by the angular direction $\gamma_{\mathrm{K}}$

$$
\begin{aligned}
v_{\kappa}^{2} & =v_{A}{ }^{2}+v^{2}+2 v_{A} v \cos \left(\gamma_{A}-\psi+\beta\right), \gamma_{\kappa}= \\
& =\arccos \left(\left(v+v_{A} \cos \left(\gamma_{A}-\psi+\beta\right)\right) / v_{\kappa}\right)-\beta,
\end{aligned}
$$

where $\mathrm{v}$ is the module of the vessel's velocity. follows

Aerodynamic accelerations in the body-fixed system of reference are expressed as

$$
a_{x A}=C_{x A} S_{x A} q_{A} / m_{11}, a_{y A}=C_{y A} S_{y A} q_{A} / m_{22}, a_{\omega A}=C_{\omega A} S_{y A} q_{A} L / J_{z},
$$

where $C_{x A}, C_{y A}, C_{\omega A}$ are aerodynamic coefficients of the vessel (depending on the relative angle of the wind); $S_{x A}, S_{y A}$ is the projection area of the surface of the vessel on the mid-frame plane and on the longitudinal vertical plane; $q_{A}=\rho_{A} v_{K}^{2} / 2$ is the wind velocity.

Accelerations from sea waves are represented by constant and variable components. expressions

Accelerations of the constant component of the waves are determined by the $a_{x V 0}=0.5 C_{x V} \rho g A_{V}^{2} L / m_{11}, a_{y V 0}=0.5 C_{y V} \rho g A_{V}^{2} L / m_{22}, a_{\omega V 0}=C_{\omega V} \rho g A_{V}^{2} L^{2} / J_{z}$,

where $A_{v}$ is the amplitude of the regular wave; $\rho$ is water mass density; $g$ is the gravity factor. Wave force factors $C_{x V}, C_{y V}, C_{\omega V}$ depend on relative length of the wave $\lambda_{V} / L$ and the heading angle of the wave $\psi_{V}$. expressions

Accelerations of the variable component of the waves are determined by the $a_{y V p}=Y_{V} \cos \left(\omega_{H} t\right) / m_{22}, a_{\omega V p}=M_{V} \sin \left(\omega_{H} t\right) / J_{z}, \omega_{H}=\omega_{k}\left(1-v \omega_{k} \cos \left(\psi_{V}\right) / g\right)$,

where $Y_{V}, M_{V}$ are the amplitudes of the lateral force and the yaw moment due to the action of a regular wave; $\omega_{k}$ is the frequency of wave climb.

In collision risk assessment methods, the basic concept is the closest point of approach (CPA). It is taken into account that for safe movement, the distance of the closest approach of the vessels must be greater than a certain critical value. The following quantities are also taken into account: "time of closest point of approach (TCPA)" and "distance to closest point of approach (DCPA)". To model the risk of collision, the concept of a certain "safety zone" around each ship is used. 


\section{Synthesis of the control algorithm}

Controlled stochastic process $\Delta \hat{X}\left(t_{i}\right)=\left(\mathbf{X}_{g}(t)-\hat{X}\left(t_{i}\right), P_{0}-\hat{P}\left(t_{i}\right)\right)$, according to $[2,3]$, satisfies the vector linearized recurrent stochastic equations of the form

$$
\Delta \hat{X}\left(t_{i}\right)=\mathbf{L}\left(t_{i}, t_{i-1}\right) \Delta \hat{X}\left(t_{i-1}\right)+\mathbf{B}\left(t_{i}\right) \Delta \mathbf{U}\left(t_{i}\right)+\boldsymbol{\Sigma}\left(t_{i}\right) \xi\left(t_{i}\right), \quad \Delta \hat{X}\left(t_{0}\right)=0,
$$

where transfer matrix $\mathbf{L}\left(t_{i}, t_{i-1}\right)$ taking into account the current, wind and waves is determined by the expression

$$
\mathbf{L}_{\mathrm{T}}\left(\mathrm{t}_{\mathrm{i}}, \mathrm{t}_{\mathrm{i}-1}\right)=\left[\begin{array}{lc}
\mathbf{I}+\mathbf{A}_{\mathrm{x}}(\cdots) \mathrm{dt}, \mathbf{A}_{\mathrm{p}}(\cdots) \mathrm{dt} \\
\mathbf{0} & \mathrm{I}
\end{array}\right] .
$$

The elements of the matrices $\mathbf{A}_{x}(\ldots), \mathbf{A}_{p}(\ldots)$ are partial derivatives of the accelerations of the coordinates of the phase vector $X(t)$. Nonzero elements of the matrices $A x(\ldots), A p(\ldots)$ are given [18-20].

To solve the synthesis problem, we will use the Bellman R. method of dynamic programming, as applied to linearized stochastic processes. The optimal vector of control actions is determined by the expression

$$
\mathbf{U}^{*}\left(t_{i}\right)=\mathbf{U}_{0}\left(t_{i}\right)+\mathbf{S}\left(t_{i}\right) \Delta \hat{X}_{r}\left(t_{i}\right) .
$$

The gain matrix of the control device $\mathbf{S}\left(\mathrm{t}_{\mathrm{i}}\right)$ is determined by

$$
\mathbf{S}\left(t_{i}\right)=-\left(\mathbf{G}\left(t_{i}\right)+\mathbf{B}^{T}\left(t_{i}\right) \mathbf{R}\left(t_{i+1}\right) \mathbf{B}\left(t_{i}\right)\right)^{-1} \mathbf{B}^{T}\left(t_{i}\right) \mathbf{R}\left(t_{i+1}\right) \mathbf{L}\left(t_{i+1}, t_{i}\right) .
$$

Matrix $\mathbf{R}\left(t_{i+1}\right)$ satisfies the recurrent equation

$$
\begin{aligned}
\mathbf{R}\left(t_{i}\right)= & \mathbf{L}^{T}\left(t_{i+1}, t_{i}\right) \mathbf{R}\left(t_{i+1}\right) \mathbf{L}\left(t_{i+1}, t_{i}\right)+\mathbf{Q}\left(t_{i}\right)- \\
& -\mathbf{S}^{T}\left(t_{i}\right)\left(\mathbf{G}\left(t_{i}\right)+\mathbf{B}^{T}\left(t_{i}\right) \mathbf{R}\left(t_{i+1}\right) \mathbf{B}\left(t_{i}\right)\right) \mathbf{S}\left(t_{i}\right),
\end{aligned}
$$

with the boundary condition $\mathbf{R}(T)=0$.

\section{Control algorithm accuracy analysis}

The accuracy analysis of the algorithms was carried out by the method of statistical modeling for a vessel of the Volga-Balt type during the passage of the Kerch - Yenikalsky canal. The Table 3 shows the characteristics of weather conditions.

Table 3 The characteristics of weather conditions

\begin{tabular}{|l|l|l|l|l|l|l|}
\hline $\mathbf{v T}[\mathbf{m} / \mathbf{s}]$ & $\boldsymbol{\psi T}_{\mathrm{T}}(\mathbf{x})[\mathbf{r a d}]$ & $\mathbf{v}_{\mathrm{A}}[\mathbf{m} / \mathbf{s}]$ & $\gamma_{\mathrm{A}}[$ degree$]$ & $\mathbf{A}_{\mathbf{v}}[\mathbf{m}]$ & $\boldsymbol{\psi v}_{\mathbf{V}}[$ degree$]$ & $\boldsymbol{\omega}_{\mathbf{k}}[\mathbf{r a d} / \mathbf{s}]$ \\
\hline 0.6 & $0.000618 \mathrm{x}$ & 15 & 30 & 0.5 & 30 & 0.5 \\
\hline
\end{tabular}

The parameters and characteristics of the vessel's motion were determined in accordance with as [15-17]. As the control action, the angular position of the rudder of the 
vessel $U(t)=\delta(t)$ was considered, the number of revolutions of the vessel's engine was considered constant $(\mathrm{n}$ rev $=3.5 \mathrm{r} / \mathrm{s}$ ). The risk of steering during the passage of the canal was considered as

$$
\begin{aligned}
\mathrm{R}_{U}= & \int_{t_{0}}^{\mathrm{T}}\left[\mathrm{q}_{22}\left(\mathrm{y}_{g}(\tau)-\hat{\mathrm{y}}(\tau)\right)^{2}+\mathrm{q}_{44}\left(\mathrm{v}_{\mathrm{yg}}(\tau)-\hat{\mathrm{v}}_{\mathrm{y}}(\tau)\right)^{2}+\right. \\
& \left.+\mathrm{q}_{55}\left(\psi_{\mathrm{g}}(\tau)-\hat{\psi}(\tau)\right)^{2}+g \delta^{2}(\tau)\right] \mathrm{d} \tau,
\end{aligned}
$$

Where $q_{22}=0.041 / \mathrm{m}^{2}, q_{44}=100 \mathrm{~m}^{2} / \mathrm{s}^{2}, q_{55}=36001 / \mathrm{rad}^{2}, g=41 / \mathrm{rad}^{2}$.

The optimal angular position of the rudder was formed according to the expression

$$
\delta(t)=\delta_{o}(t)+s_{2}(t)\left(y_{g}(t)-(t)\right)+s_{4}(t)\left(v_{y g}(t)-(t)\right)+s_{5}(t)\left(\Psi_{g}(t)-(t)\right) .
$$

Figure 2 shows the trajectory of the vessel during the passage of the channel.

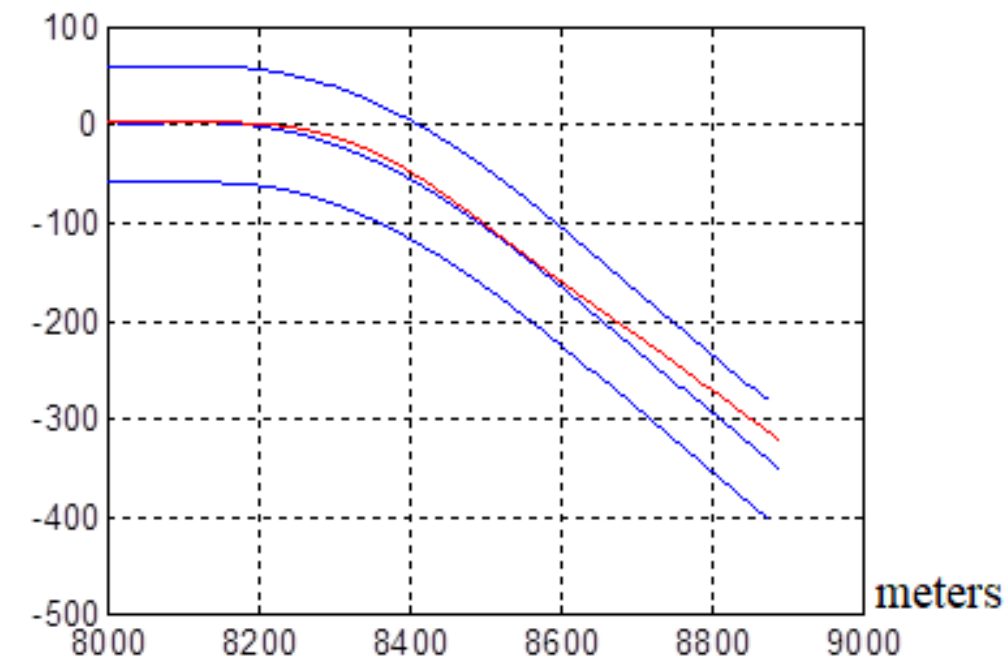

Fig. 3 The trajectory of the vessel during the passage of the channel

The paper analyzes the exposure of the outermost dimensional point of the vessel [8] beyond the fairway lane of $30 \mathrm{~m}$ at half the strait width of $60 \mathrm{~m}$. The real distance between the overall point of the vessel and the fairway line was calculated using the approximate formula [20]

$$
\begin{aligned}
l_{g t}(t) & =y_{g}(t)-y(t)+\left(L \sin \left(\left|\Psi_{g}(t)-(t)\right|\right)+B \cos \left(\Psi_{g}(t)-\right.\right. \\
& -(t))) \operatorname{sign}\left(y_{g}(t)-y(t)\right),
\end{aligned}
$$

where $\mathrm{L}$ and $\mathrm{B}$ are the length and width of the vessel.

The situation, when $l_{g t}(t) \mid>30 \mathrm{~m}$ and $|\delta(t)|>20^{\circ}$ is considered to be dangerous. The probability of a dangerous passage of the channel under specific weather conditions was calculated for $10 \%$ of the deviations of the random parameters $\mathbf{P}=\left[m_{11}, m_{22}, J_{z}\right]$ from the calculated ones, using the statistical modeling method. Figure 4 shows the probability of a dangerous situation when passing the canal. 
Ivanovsky Nikolay, Chernyi Sergei,

Sokolov Sergey, Zhilenkov Anton, Zhinchenko Anton
Algorithm design for ship's steering with specified limitations under various weather conditions

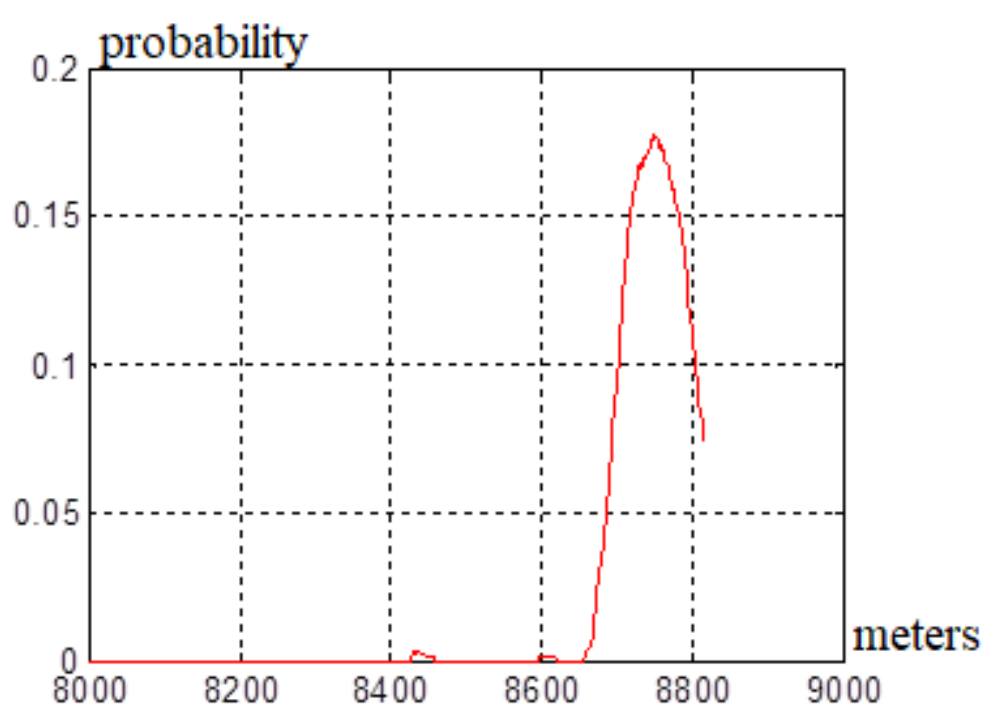

Fig. 4 The probability of a dangerous situation during the passage of the canal

It is possible, using simple linear estimation algorithms [15], to construct estimates of velocities $\hat{v}_{x}\left(t_{i}\right), \hat{v}_{y}\left(t_{i}\right)$ and angular velocity $\hat{\omega}\left(t_{i}\right)$. For velocity $v_{x}(t)$ (similarly $v_{y}(t)$, $\omega(t))$ is determined:

$$
K_{v}\left(t_{i} \mid t_{i-1}\right)=K_{v}\left(t_{i-1}\right)+\sigma_{a}^{2}, \quad P_{v}\left(t_{i}\right)=K_{v}\left(t_{i} \mid t_{i-1}\right) /\left(K_{v}\left(t_{i} \mid t_{i-1}\right)+\sigma_{v}^{2}\right), \quad K_{v}\left(t_{0}\right)=\sigma_{v}^{2} \quad \text { and }
$$

$\hat{v}_{x}\left(t_{i}\right)=\hat{v}_{x}\left(t_{i-1}\right)+a_{x}^{*}\left(t_{i-1}\right) d t+P_{v}\left(t_{i}\right)\left(v_{x}^{*}\left(t_{i}\right)-\hat{v}_{x}\left(t_{i}\right)\right), \quad K_{v}\left(t_{i}\right)=K_{v}\left(t_{i} \mid t_{i-1}\right)-P_{v}\left(t_{i}\right) K_{v}\left(t_{i} \mid t_{i-1}\right)$

where $K_{v}\left(t_{i}\right)$ is the velocity estimation variance and $d t=t_{i}-t_{i-1}$ is the measurement arrival time interval. Realizations of the estimates of speeds and angular velocity when simulating the rectilinear motion of a Volgo-Balt-type vessel are shown in Figures 1-4 at full speed (Figure 1) and during circulation (Figures 5-7). Measurement accuracies are $\sigma_{v}=0.1 \mathrm{~m} / \mathrm{s}$, $\sigma_{a}=0.01 \mathrm{~m} / \mathrm{s}^{2}$, time interval $d t=0.5 \mathrm{~s}$.

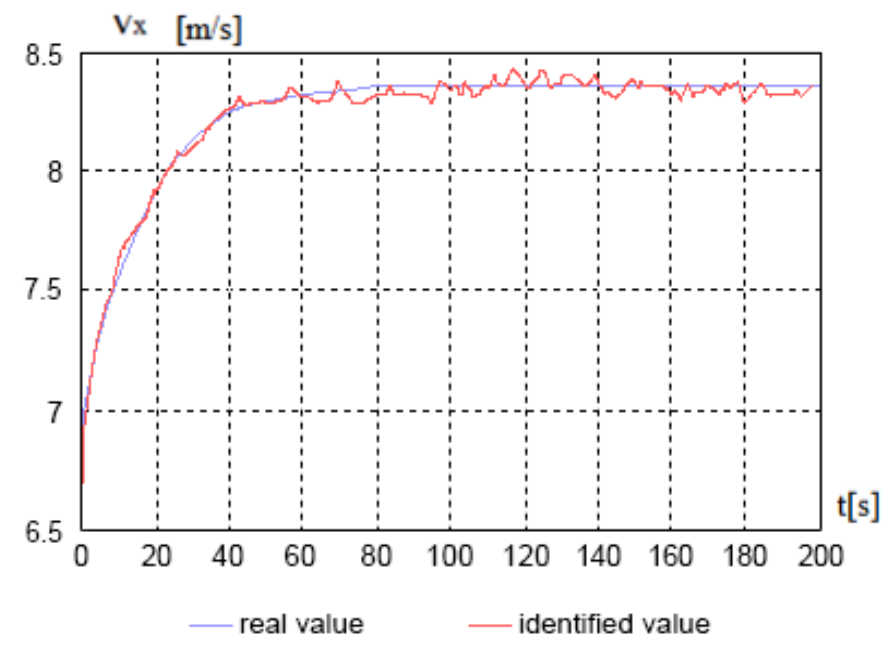

Fig. 5 The speed of rectilinear movement 
Ivanovsky Nikolay, Chernyi Sergei,

Sokolov Sergey, Zhilenkov Anton, Zhinchenko Anton
Algorithm design for ship's steering with specified limitations under various weather conditions

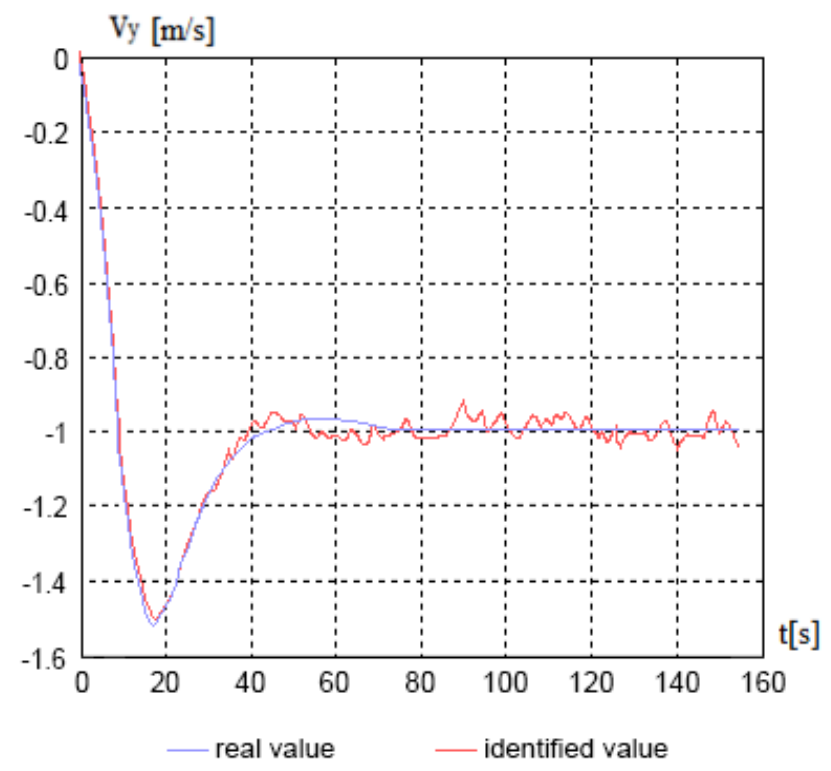

Fig. 6 Boundary values of the indicator

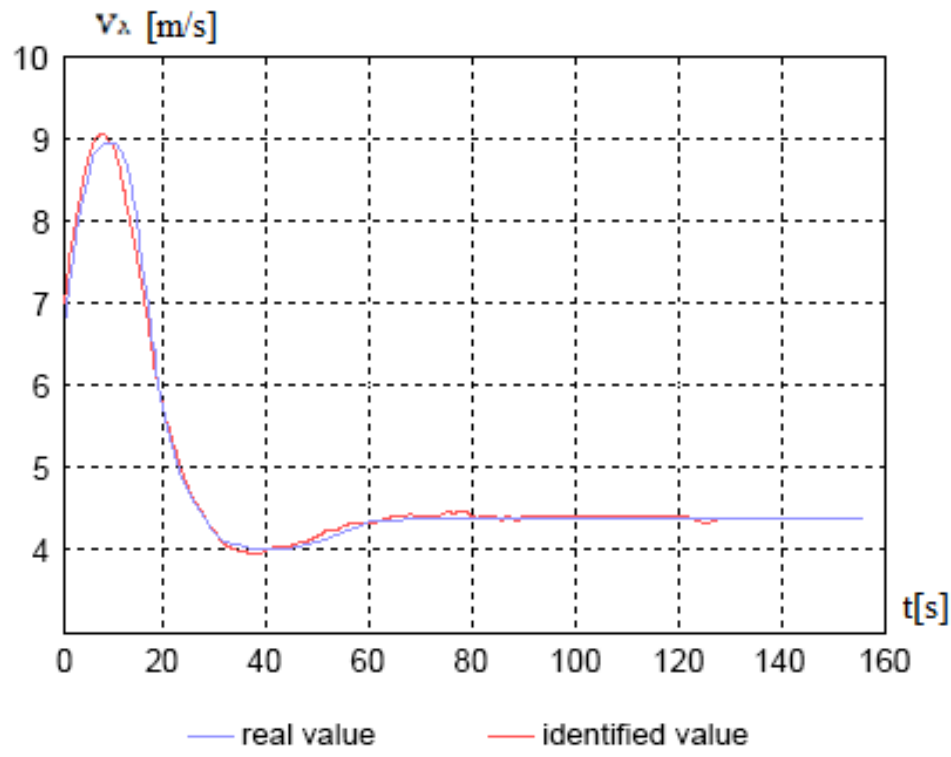

Fig. 7 Simulation model and real model

\section{Conclusions}

When using the ship motion model, the question arises of the correspondence of the modeled phase coordinates of the ship motion to the real motion of the ship and the category of risk of maneuver. A number of ship parameters used in the ship motion model are set in the form of a priori values and require clarification based on field information in the process of testing the automated control system. To solve such a problem, synthesis models were applied, algorithms for estimating a priori parameters of a movement model based on fullscale information of a ship's movement with an element of risk influence. 
Ivanovsky Nikolay, Chernyi Sergei,

Sokolov Sergey, Zhilenkov Anton, Zhinchenko Anton
Algorithm design for ship's steering with specified limitations under various weather conditions

The research provides a solution to the problem of synthesizing an optimal vessel steering algorithm according to the criterion of the mean square risk value when passing through narrow straits under various weather conditions. For the synthesized algorithm, statistical modeling of calculating the probability of a dangerous situation passing through the strait was carried out. Thus, for example, the probability of a dangerous situation in the passage of the Kerch - Yenikalsky Canal by a Volga-Balt type vessel when the vector of random parameters $\mathbf{P}=\left[m_{11}, m_{22}, J_{z p}\right]$ deviates from the calculated up to $10 \%$ is no more than 0.17 for certain weather conditions in the area of 8650-8800 m.

Funding: The research is partially funded by the Ministry of Science and Higher Education of the Russian Federation as part of the World-class Research Center program: Advanced Digital Technologies (contract No. 07515-2020-903 dated 16.11.2020)

\section{REFERENCES}

[1] Transport of Russia. Statistical Newsletter. https://www.mintrans.ru/ministry/results/180/documents

[2] Vinogradov, V.N., Ivanovsky, N.V., Novoselov, D.A. (2018). Analysis of the effect of random vessel parameters on steering capabilities and safety. Journal Vestnik of Volga State Academy of Water Transport. Issue 55:78-84.

[3] Yu, Q., Liu, K., Yang, Z., Wang, H., \& Yang, Z. (2021). Geometrical risk evaluation of the collisions between ships and offshore installations using rule-based Bayesian reasoning. Reliability Engineering \& System Safety, 210, 107474. https://doi.org/10.1016/j.ress.2021.107474

[4] Zhang, M., Montewka, J., Manderbacka, T., Kujala, P., \& Hirdaris, S. (2021). A Big Data Analytics Method for the Evaluation of Ship - Ship Collision Risk reflecting Hydrometeorological Conditions. Reliability Engineering \& System Safety, 213, 107674. https://doi.org/10.1016/j.ress.2021.107674

[5] Xin, X., Liu, K., Yang, Z., Zhang, J., \& Wu, X. (2021). A probabilistic risk approach for the collision detection of multi-ships under spatiotemporal movement uncertainty. Reliability Engineering \& System Safety, 215, 107772. https://doi.org/10.1016/j.ress.2021.107772

[6] Cheng, X., Li, G., Skulstad, R., Major, P., Chen, S., Hildre, H., \& Zhang, H. (2019). Data-driven uncertainty and sensitivity analysis for ship motion modeling in offshore operations. Ocean Engineering, 179, 261-272. https://doi.org/10.1016/j.oceaneng.2019.03.014

[7] Gil, M. (2021). A concept of critical safety area applicable for an obstacle-avoidance process for manned and autonomous ships. Reliability Engineering \& System Safety, 214, 107806. https://doi.org/10.1016/j.ress.2021.107806

[8] Vinogradov V.N., Ivanovsky N.V. (2018). Synthesis of algorithms for identifying random parameters and evaluating the characteristics of the vessel. Journal Vestnik of Volga State Academy of Water Transport. Issue 55:45-77.

[9] Zubowicz, T., Armiński, K., Witkowska, A., \& Śmierzchalski, R. (2019). Marine autonomous surface ship - control system configuration. IFACPapersonline, 52(8), 409-415. https://doi.org/10.1016/j.ifacol.2019.08.100

[10] Cha, R., \& Wan, D. (2015). Numerical Investigation of Motion Response of Two Model Ships in Regular Waves. Procedia Engineering, 116, 20-31. https://doi.org/10.1016/j.proeng.2015.08.260

[11] Kramar, V. (2016). Investigation of Changes and Development of Mathematical Model for a Drilling Vessel. DAAAM Proceedings, 0049-0055. https://doi.org/10.2507/26th.daaam.proceedings.007

[12] Dmitriev, S.P., Peleven, A.E. Tasks of navigation and steering during stabilization of the vessel on the trajectory. Electropribor. 2004.

[13] Geertsma, R., Negenborn, R., Visser, K., \& Hopman, J. (2017). Design and control of hybrid power and propulsion systems for smart ships: A review of developments. Applied Energy, 194, 30-54. https://doi.org/10.1016/j.apenergy.2017.02.060 
Ivanovsky Nikolay, Chernyi Sergei,

Sokolov Sergey, Zhilenkov Anton, Zhinchenko Anton
Algorithm design for ship's steering with specified limitations under various weather conditions

[14] Glebov, N., Zhilenkov, A., Chernyi, S., \& Sokolov, S. (2019). Process of the Positioning Complex Modeling Objects with Elements of Intellectual Analysis. Procedia Computer Science, 150, 609-615. https://doi.org/10.1016/j.procs.2019.02.094

[15] Ivanovskii, N.; Chernyi, S.G.; Zhilenkov, A.; Emelianov, V. (2021) Development of Algorithms for Identifying Parameters of the Maritime Vessel Motion Model in Operating Conditions with Elements of Intellectual Analysis. J. Mar. Sci. Eng. 2021, 9, 418. https://doi.org/10.3390/jmse9040418

[16] Kalman R. E., Bucy R. S. (1961). New results in the theory of linear filtering and prediction. Theoretical foundations of engineering calculations. Moscow. No. 1. https://doi.org/10.1115/1.3658902

[17] Vinogradov, V.N. Correlation theory of filtration and control of multidimensional random processes. Moscow: Krasand. 2011.

[18] Nyrkov, A., Zhilenkov, A., Sokolov, S., \& Chernyi, S. (2018). Hard- and Software Implementation of Emergency Prevention System for Maritime Transport. Automation And Remote Control, 79(1), 195202. https://doi.org/10.1134/S0005117918010174

[19] Bashan, V, Demirel, H, Gul, M. (2020) Novel risk evaluation approach for frequently encountered risks in ship engine rooms. Brodogradnja Vol.71, Issue2, Page31-54. https://doi.org/10.21278/brod71203

[20] Tian, WL; Ma, QD; Meng, BB; Zhang, JF; Gan, ZB; Wan, H; (2020) Ship collision risk assessment model for qinzhou port based on event sequence diagram. Brodogradnja. Vol.71, Issue 2, 1-14. https://doi.org/10.21278/brod71201

Submitted: $\quad$ 02.05. 2021. Corresponding Author: Sergei G. Chernyi, PhD sergiiblack@gmail.com

Accepted: 29.10.2021. Nikolay Ivanovsky

Department of Navigation and Commercial Fisheries, Kerch State Maritime technological University, Russia; inv8@mail.ru

Sergei Chernyi

Admiral Makarov State University of Maritime and Inland Shipping,

St.Petersburg, Russia

Kerch State Maritime technological University, Russia

St. Petersburg State Marine Technical University, Russia;

sergiiblack@gmail.com

Sergey Sokolov

Admiral Makarov State University of Maritime and Inland Shipping,

St.Petersburg, Russia; sokolovss@gumrf.ru

Anton Zhilenkov

Department of Cyber-Physical Systems, St. Petersburg State Marine Technical University, Saint-Petersburg, Russia; zhilenkovanton@gmail.com

Anton Zinchenko

Department of Cyber-Physical Systems, St. Petersburg State Marine Technical University, Saint-Petersburg, Russia;

Admiral Makarov State University of Maritime and Inland Shipping,

St.Petersburg, Russia

Antel85@bk.ru 